\title{
Diabetic Gastroparesis Presenting with a Cyclic Vomiting Pattern
}

\author{
Yong Jin Nam, Sung Eun Kim, Moo In Park, Seun Ja Park, Won Moon, Jae Hyun Kim, Kyoungwon Jung, Sangeon Gwoo \\ Department of Internal Medicine, Kosin University College of Medicine, Busan, Korea
}

\begin{abstract}
Gastroparesis is a syndrome characterized by delayed gastric emptying in the absence of mechanical obstruction of the stomach. Approximately $20 \sim 40 \%$ of patients with a long course of diabetes mellitus and/or other complications, especially neurologic dysfunction, develop diabetic gastroparesis. Diabetic gastroparesis has been thoroughly investigated; however, few reports have considered an associated episodic cyclic vomiting pattern. We present a literature review and report the case of our recent experience with a 29-year-old male patient who presented with a cyclic vomiting pattern associated with diabetic gastroparesis. (Korean J Helicobacter Up Gastrointest Res 2017;17:148-153)
\end{abstract}

Key Words: Cyclic vomiting syndrome; Diabetes mellitus; Gastroparesis

\section{INTRODUCTION}

Cyclic vomiting syndrome (CVS) is a disorder characterized by recurrent episodes of severe nausea and vomiting interspersed with symptom-free periods. Rome IV criteria defines it in more detail, CVS must include all of the following 3 criteria: 1) CVS is stereotypical episodes of vomiting concerning acute onset and duration with less than 1 week, 2) the symptoms are at least e discrete episodes in the last year and 2 episodes in the past 6 months, occurring at least 1 week apart, 3) there was no vomiting between episodes, but other milder symptoms can occur between cycles. ${ }^{1}$ This syndrome was initially described in literature in 1882 by Gee, ${ }^{2}$ who reported a series of 4- to 8-year-old children experiencing recurrent emetic episodes. While CVS has been studied in pediatric populations, it can occur in all age groups, including young and middle-aged adults. Prevalence of CVS in adults is increasing, but the lack of awareness of CVS in adults has led to delay in diagnosis or misdiagnosis. Some evidence suggests that there are differences in terms of symptom profiles, pathogenesis, and comorbidities between adults and children. ${ }^{3}$ In contrast to most childhood cases, CVS in adults is associated with a number of un-

Received: April 10, 2017 Revised: July 5, 2017 Accepted: July 7, 2017

Corresponding author: Sung Eun Kim

Department of Internal Medicine, Kosin University Gospel Hospital, 262 Gamcheon-ro, Seo-gu, Busan 49267, Korea

Tel: +82-51-990-5205, Fax: +82-51-990-5055, E-mail: solefide@hanmail.net derlying chronic systemic diseases including diabetes mellitus (DM). ${ }^{4}$

Gastroparesis is a syndrome characterized by delayed gastric emptying in absence of mechanical obstruction of the stomach. Its actual prevalence is unknown. However, it is estimated that $20 \%$ to $40 \%$ of patients with diabetes, primarily those with a long duration of type $1 \mathrm{DM}$ with other complications, develop gastroparesis. ${ }^{5}$ Diabetic gastroparesis has been thoroughly investigated, but few reports have considered episodic CVS. A recent article initially dealt with a subset of patients with a cyclic vomiting pattern in a population of patients with diabetic gastroparesis. ${ }^{3}$ We describe a case of severe diabetic gastroparesis presenting with a cyclic vomiting pattern.

\section{CASE REPORT}

A 29-year-old male was admitted for evaluation of recurrent episodes of severe nausea and vomiting for 2 years. He had been diagnosed with type $1 \mathrm{DM}$ at another hospital 7 years previous. He received insulin injection 3 times daily (mixture of 50\% rapid-acting and 50\% intermediate-acting insulin, and the dose of insulin was 30 unit-20 unit-20 unit) without an oral hypoglycemia agent. However, he had overeating behaviors and his blood glucose levels showed unstable. At the current presentation, he denied other underlying diseases including hypertension, tuberculosis, and hepatitis. He also denied history

Copyright $\odot 2017$ Korean College of Helicobacter and Upper Gastrointestinal Research

() The Korean Journal of Helicobacter and Upper Gastrointestinal Research is an Open-Access Journal. All articles are distributed under the terms of the Creative Commons Attribution Non-Commercial License (http://creativecommons.org/licenses/by-nc/4.0) which permits unrestricted non-commercial use, distribution, and reproduction in any medium, provided the original work is properly cited. 
of substance abuse including marijuana or opioid. He had no siblings and no family history of DM or genetic disease. He complained of periodic severe nausea and vomiting symptoms that lasted 3 or 4 days. He was not able to eat during these periods due to persistent nausea, repeated vomiting, and abdominal pain. After such an emetic phase, the symptoms resolved, and the patient showed good health for several weeks to months. These symptoms tended to occur when the patient was in a postprandial state, but there was no specific trigger or aggravating factor. He had previously been admitted to another hospital with these symptoms 1 month prior to the visit to our hospital and underwent esophagogastroduodenoscopy. The endoscopic findings were compatible
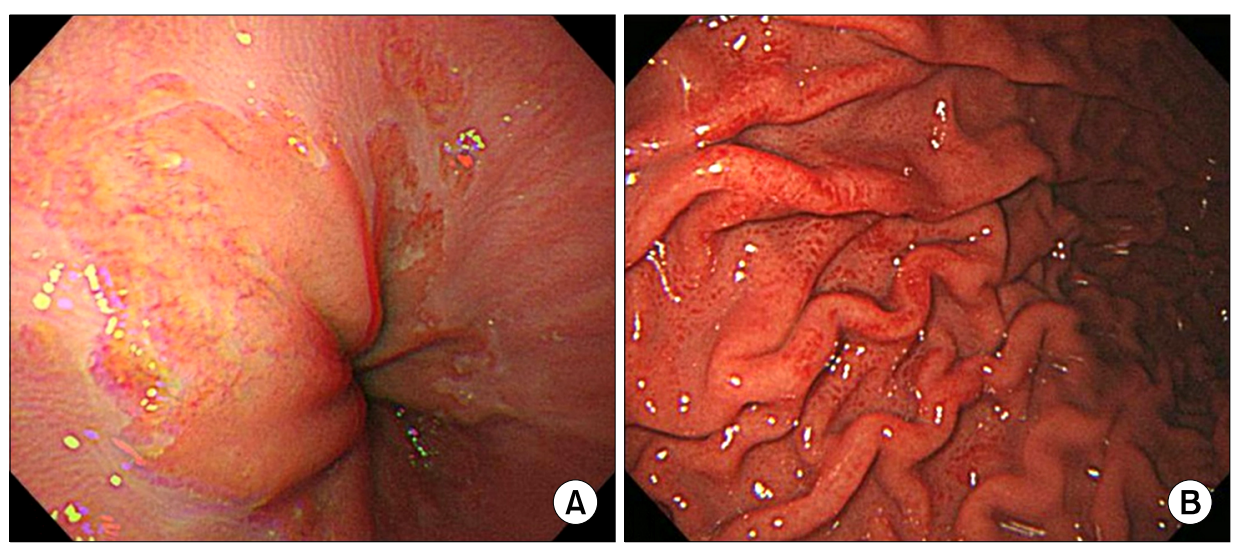

Fig. 1. Esophagogastroduodenoscopy shows reflux esophagitis (A) and diffuse mild hyperemic gastric mucosa at the mid-body of the greater curvature, compatible with erythematous gastritis (B).

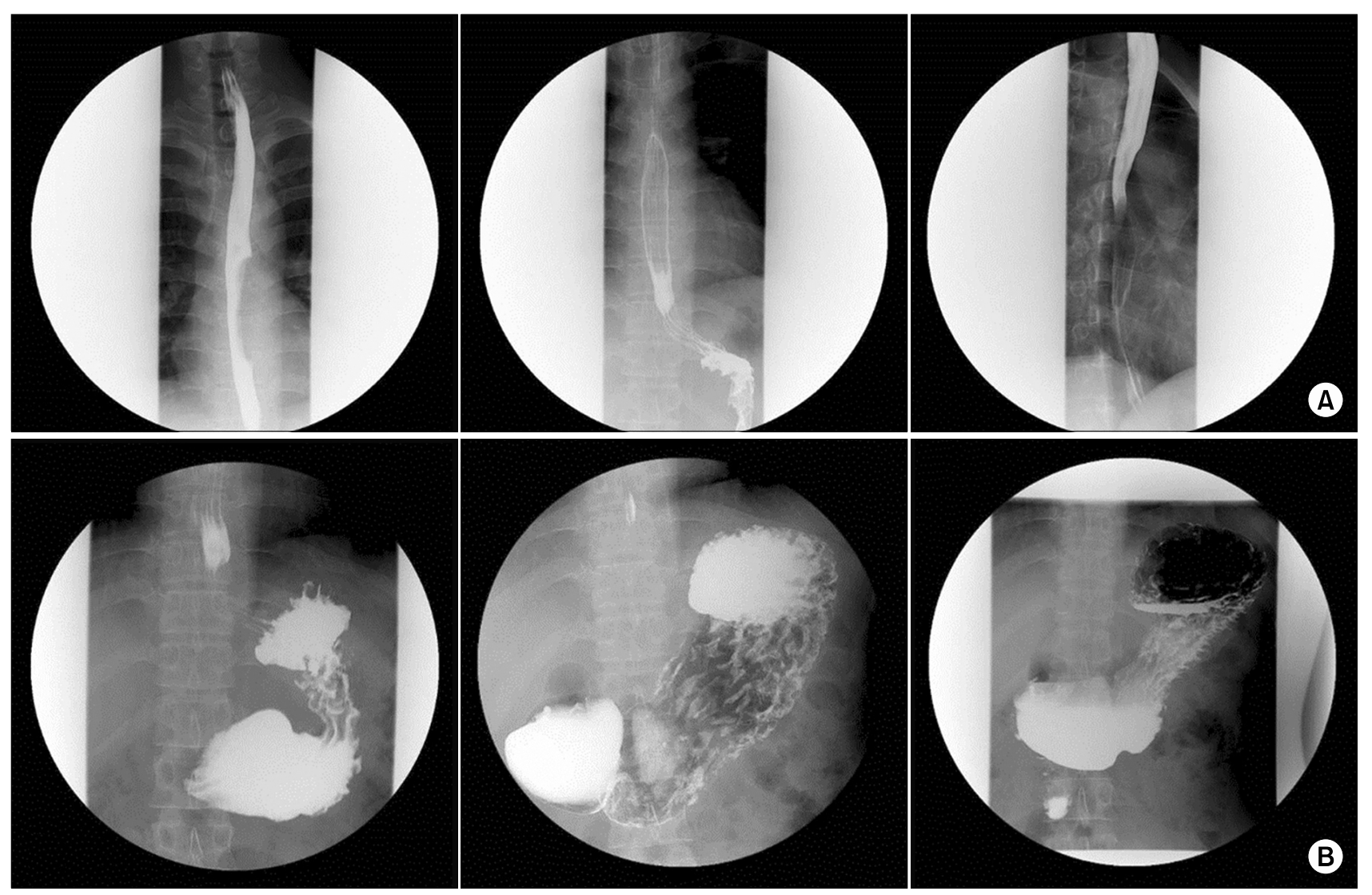

Fig. 2. The esophagogram shows normal course, good distensibility, and smooth passage of contrast media with good peristaltic movement (A). Upper gastrointestinal series also shows normal mucosal folds with no filling defect or narrowing (B). 
with reflux esophagitis and erythematous gastritis, for which he was prescribed ranitidine, mosapride, and trimebutine maleate for 5 days, resulting in symptom resolution. He was free of nausea and vomiting for about 1 month, but then the symptoms relapsed. He revisited the previous hospital and again underwent esophagogastroduodenoscopy. The endoscopic findings showed no significant interval change. Therefore, abdominal computed tomography was performed and showed no evidence of mechanical obstructive lesion. He was then transferred to our hospital and admitted.

His height was $171 \mathrm{~cm}$, and body weight was $75 \mathrm{~kg}$. Blood pressure was $131 / 77 \mathrm{mmHg}$, heart rate $72 / \mathrm{min}$, respiratory rate $18 / \mathrm{min}$, and body temperature $36.4^{\circ} \mathrm{C}$, and there were no abnormal findings on physical examination. Laboratory findings revealed elevated fasting blood sugar of $226 \mathrm{mg} / \mathrm{dL}$ and glycosylated hemoglobin (HbA1c) of $7.9 \%$. In addition, his blood hemoglobin was $14.4 \mathrm{~g} / \mathrm{dL}$, white blood cell count $11,400 / \mathrm{mm}^{3}$ (neutrophils $81.5 \%$, lymphocytes $12.3 \%$, monocytes $4.3 \%$, eosinophils $0.2 \%$, and basophil $1.7 \%$ ), platelet count $355,000 / \mathrm{mm}^{3}$, blood urea nitrogen $9.0 \mathrm{mg} / \mathrm{dL}$, creatinine $0.7 \mathrm{mg} / \mathrm{dL}$, total pro- tein $6.7 \mathrm{~g} / \mathrm{dL}$, albumin $4.5 \mathrm{~g} / \mathrm{dL}$, AST $13 \mathrm{IU} / \mathrm{L}$, ALT $8 \mathrm{IU} / \mathrm{L}$, total bilirubin $1.0 \mathrm{mg} / \mathrm{dL}$, direct bilirubin $0.3 \mathrm{mg} / \mathrm{dL}$, GGT 12 IU/L, ALP 48 IU/L, total amylase $79 \mathrm{mg} / \mathrm{dL}$, lipase 31 mg/dL, CEA 2.08 $\mu \mathrm{g} / \mathrm{L}$, CA 19-9 24.87 U/mL, ACTH 15.7 $\mathrm{pg} / \mathrm{mL}$, and cortisol $9.88 \mu \mathrm{g} / \mathrm{dL}$. Serologic markers for $\mathrm{HBV}, \mathrm{HCV}$, human immunodeficiency virus, and venereal disease research laboratory test were normal. Esophagogastroduodenoscopy showed reflux esophagitis and erythematous gastritis without significant interval change (Fig. 1). Esophagogram and upper gastrointestinal series showed normal anatomic findings without filling defect or narrowing (Fig. 2). With high suspicion of gastrointestinal motility disorder, we performed a gastric emptying time scan at the emetic phase, and gastric emptying half-time was 325.21 minutes (Fig. 3). In addition, we conducted an autonomic function test, nerve conduction study, and ophthalmoscopy. The findings were compatible with parasympathetic cardiovagal dysfunction, peripheral polyneuropathy, and severe non-proliferative diabetic retinopathy.

We controlled his blood sugar with insulin injection 4 times daily by using multiple subcutaneous insulin in-

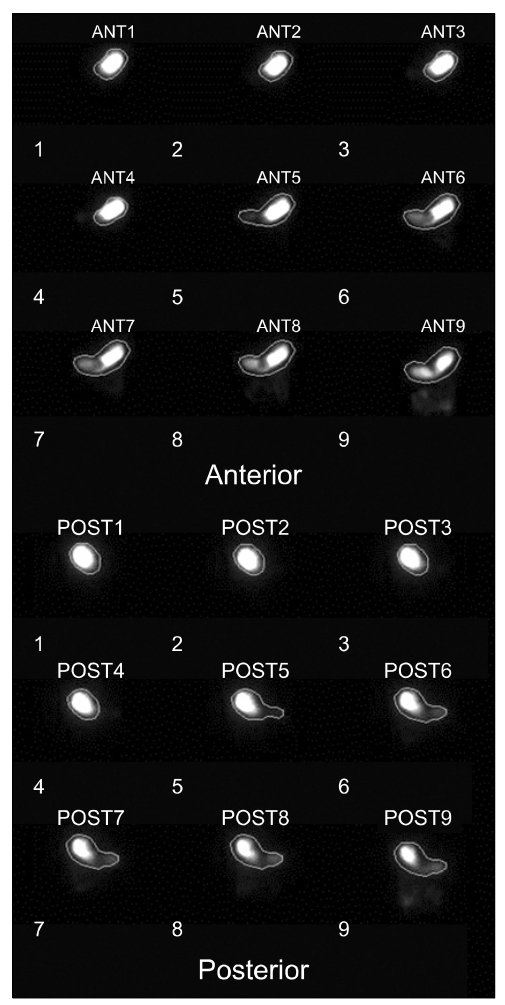

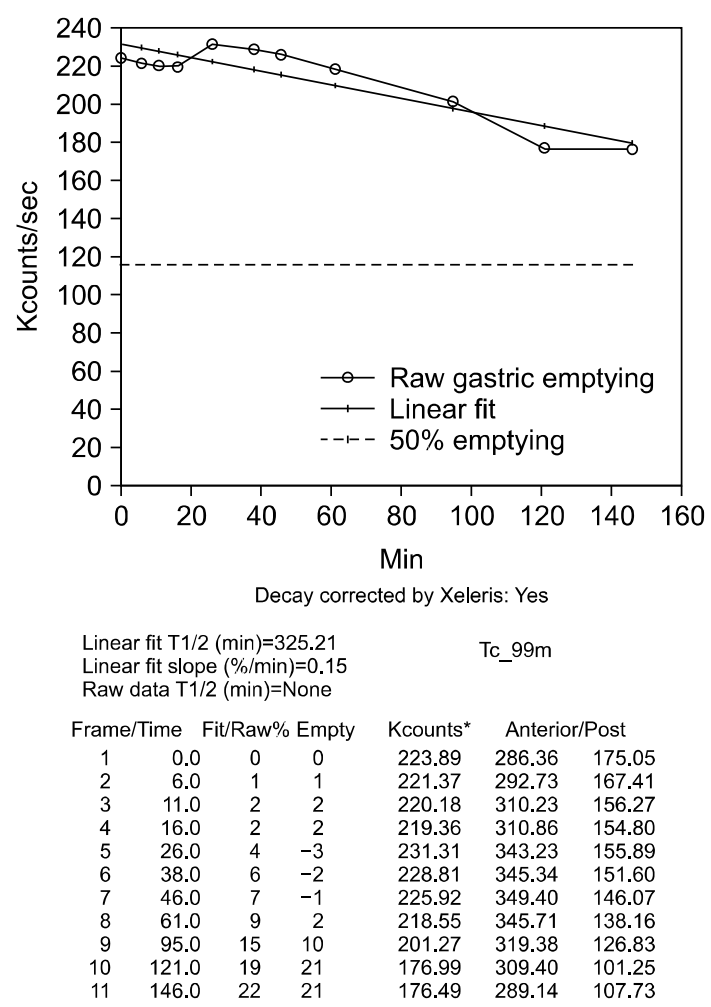

Fig. 3. The scintiscanning of gastric emptying time shows a severe delayed half-time of gastric emptying $(\mathrm{T} 1 / 2=$ 325.21 min). *Geometric mean. 
fection protocol (24 unit long-acting insulin once every morning and 10 unit three times injections of every pre-prandial rapid-acting insulin). In addition, we prescribed metoclopramide $5 \mathrm{mg}$ tid, domperidone $10 \mathrm{mg}$ tid, mosapride $5 \mathrm{mg}$ tid, and amitriptyline $10 \mathrm{mg}$ qd for diabetic gastroparesis with a cyclic vomiting pattern. When he was discharged, his clinical symptoms were improved after proper diagnosis and management based on careful history taking. He visited our outpatient department twice after discharge during 1 month and there was no symptoms recurrence in the interim. Unfortunately, he was lost to follow-up in our hospital.

\section{DISCUSSION}

Gastroparesis is a syndrome characterized by delayed gastric emptying without gastric mechanical obstruction. ${ }^{6}$ This syndrome typically shows clinical symptoms of early satiety, nausea, vomiting, and bloating. ${ }^{7}$ The pathophysiology of gastroparesis is complex and poorly understood. However, diabetes accounted for almost one-third of cases of gastroparesis, and other causes include previous gastric surgery, neurologic disorder, rheumatologic disorder, and viral infection. Development of diabetic gastroparesis is associated with duration of diabetes and it can cause severe symptoms and result in nutritional compromise, impaired glucose control, and a poor quality of life. ${ }^{8}$ About $5 \%$ to $12 \%$ of patients with diabetes in previous studies complained of symptoms associated with diabetic gastroparesis. ${ }^{9-12}$ In patients with diabetic gastroparesis, mechanisms of gastrointestinal motility are altered, mainly due to vagal neuropathy, reductions in the number of intrinsic inhibitory neurons that coordinate motor function ${ }^{13}$ and the number of the interstitial cells of Cajal as pacemaker cells, ${ }^{14}$ and hormonal changes like increased glucagon level. Chronic exposure to high blood glucose increases the risk of diabetic neuropathy including gastrointestinal symptoms. Furthermore, acute hyperglycemia can affect motor dysfunction in patients with diabetes. ${ }^{15}$ Neurohormonal dysfunction and hyperglycemia also reduce the frequency of antral contractions for churning food. In contrast, the emptying of liquids is usually normal in patients with hyperglycemia. ${ }^{16}$
Christensen et al. ${ }^{3}$ reported that a sizeable percentage of diabetic gastroparesis patients demonstrate cyclic vomiting symptoms. Their study included 67 patients with diabetic gastroparesis, and 38 (56.7\%) showed a cyclic vomiting pattern. The group showing cyclic vomiting associated with diabetic gastroparesis had a female predominance (28 patients, $73.7 \%$ ), a mean age of $43.7 \pm 1.5$ years, mean duration of diabetes of $17.8 \pm 1.8$ years, mean duration of diabetic gastroparesis of $4.7 \pm 0.6$ years, and HbA1c of $8.4 \pm 0.3 \%$. Comparing these data with that of our patient, he was diagnosed at a younger than average age, with short durations of diabetes and diabetic gastroparesis, and had low HbA1c. Nevertheless, he developed gastroparesis with a cyclic vomiting pattern.

The main strategy in the management of diabetic gastroparesis is the correction of exacerbating factors such as glucose and electrolyte abnormalities, optimal nutritional support, and the use of prokinetic agents and symptomatic therapies. Moreover, previous medications can delay gastric emptying time, such as antihypertensive agents as calcium-channel blockers or clonidine, anticholinergic agents, and antidiabetic glucagon-like peptide-1 analogues as exenatide or pramlintide. Typically, severity of diabetic gastroparesis is determined according to gastric retention at 4 hours. When gastric retention is more than 35 percent at 4 hours, the condition is considered severe gastroparesis. ${ }^{17}$ The current case showed a severe delayed half-time of gastric emptying (T1/2=325.21 minutes). According to the severity of the condition, we prescribed prokinetics and a parenteral nutritional agent with additional liquid nutrient supplements.

Cyclic vomiting, although classically associated with migraine, has also been linked to food allergy and mitochondrial, metabolic, and endocrine disorders, such as overreaction of the hypothalamic pituitary-adrenal (HPA) axis. ${ }^{18-21}$ In terms of the HPA axis, corticotropin releasing factor (CRF) is considered as an importance trigger for the vomiting phase starts, and it stimulates of the hypersecretion of ACTH and cortisol. ${ }^{21-23}$ The current patient did not show features of migraine and abnormal ACTH and cortisol level. Another study also reported that absence of migraine was more common in male cyclic vomiting patients associated with diabetic gastroparesis than 
in their female counterparts. ${ }^{3}$ Previous studies have postulated that autonomic dysfunction and vagal cholinergic dysfunction can occur in CVS and migraine. ${ }^{24,25}$ Autonomic nervous system dysfunction could explain the increased gastric emptying time, and previous studies have shown that sympathetic adrenergic function, assessed as vasoconstriction to cold and postural adjustment ratio, was abnormal in patients with cyclic vomiting and migraine. In addition, vagal cholinergic function, assessed as valsalva ratio and electrocardiogram $\mathrm{R}-\mathrm{R}$ interval interval, was also lower in both cyclic vomiting and migraine patients. ${ }^{24}$ In our case, electrophysiological findings of the autonomic function test showed parasympathetic cardiovagal dysfunction. These findings suggest that treatment should focus on the autonomic and enteric nervous systems in diabetic gastroparesis patients with cyclic vomiting symptoms.

Although several empiric treatments have been effective in case series, there has been no controlled trial demonstrating a specific therapy proven to be effective for CVS. Generally, avoidance of predisposing factors; antiemetics, prokinetics, and analgesics; and nutritional support with intravenous fluids are recommended for such patients. Tricyclic antidepressants are the most commonly using drug class for prevention of cyclic vomiting episodes in adults, and it also has CRF inhibitory action. ${ }^{26} \mathrm{~A}$ recent study reported that antidepressants may be related with CRF haplotype 1 gene, ${ }^{27}$ and it might influence the central control of nausea and vomiting. These agents also play a prophylactic role in migraine, depression, anxiety and the abdominal pain associated with irritable bowel syndrome and presumably act centrally to modulate the vomiting process. ${ }^{28}$

The existence of this CVS-like subset of diabetic gastroparesis raises the question of whether these findings are a manifestation of or a response to underlying diabetic gastroparesis. Unfortunately, there has been little research on this cyclic vomiting manifestation associated with diabetic gastroparesis. Nonetheless, when physicians meet the DM patients with recurrent nausea and vomiting, they should suspect the possibility of CVS as well as diabetic gastroparesis and immediate proper management should be administered. A cyclic vomiting pattern can oc- cur even in young diabetic gastroparesis patients presenting with the associated symptoms.

\section{REFERENCES}

1. Stanghellini V, Chan FK, Hasler WL, et al. Gastroduodenal Disorders. Gastroenterology 2016;150:1380-1392.

2. Gee S. On fitful or recurrent vomiting. St Bartholomew Hosp Rev 1882;18:1-6.

3. Christensen CJ, Johnson WD, Abell TL. Patients with cyclic vomiting pattern and diabetic gastropathy have more migraines, abnormal electrogastrograms, and gastric emptying. Scand J Gastroenterol 2008;43:1076-1081.

4. Sawhney MS, Prakash C, Lustman PJ, Clouse RE. Tricyclic antidepressants for persistent or recurrent vomiting in diatetic patients. Gastroenterology 2001;120(Suppl 1):A243.

5. Parkman HP, Hasler WL, Fisher RS; American Gastroenterological Association. American Gastroenterological Association medical position statement: diagnosis and treatment of gastroparesis. Gastroenterology 2004;127:1589-1591.

6. Kassander P. Asymptomatic gastric retention in diabetics (gastroparesis diabeticorum). Ann Intern Med 1958;48:797812.

7. Revicki DA, Rentz AM, Dubois D, et al. Development and validation of a patient-assessed gastroparesis symptom severity measure: the Gastroparesis Cardinal Symptom Index. Aliment Pharmacol Ther 2003;18:141-150.

8. Talley NJ, Young L, Bytzer P, et al. Impact of chronic gastrointestinal symptoms in diabetes mellitus on health-related quality of life. Am J Gastroenterol 2001;96:71-76.

9. Enck P, Rathmann W, Spiekermann M, et al. Prevalence of gastrointestinal symptoms in diabetic patients and non-diabetic subjects. Z Gastroenterol 1994;32:637-641.

10. Janatuinen E, Pikkarainen P, Laakso M, Pyörälä K. Gastrointestinal symptoms in middle-aged diabetic patients. Scand J Gastroenterol 1993;28:427-432.

11. Maleki D, Locke GR 3rd, Camilleri M, et al. Gastrointestinal tract symptoms among persons with diabetes mellitus in the community. Arch Intern Med 2000;160:2808-2816.

12. Bytzer P, Talley NJ, Leemon M, Young LJ, Jones MP, Horowitz M. Prevalence of gastrointestinal symptoms associated with diabetes mellitus: a population-based survey of 15,000 adults. Arch Intern Med 2001;161:1989-1996.

13. Watkins CC, Sawa A, Jaffrey S, et al. Insulin restores neuronal nitric oxide synthase expression and function that is lost in diabetic gastropathy. J Clin Invest 2000;106:373-384.

14. He CL, Soffer EE, Ferris CD, Walsh RM, Szurszewski JH, Farrugia G. Loss of interstitial cells of cajal and inhibitory innervation in insulin-dependent diabetes. Gastroenterology 2001;121: 427-434.

15. Fraser RJ, Horowitz M, Maddox AF, Harding PE, Chatterton BE, Dent J. Hyperglycaemia slows gastric emptying in type 1 (insulin-dependent) diabetes mellitus. Diabetologia 1990;33: 
675-680.

16. Couturier O, Bodet-Milin C, Querellou S, Carlier T, Turzo A, Bizais Y. Gastric scintigraphy with a liquid-solid radiolabelled meal: performances of solid and liquid parameters. Nucl Med Commun 2004;25:1143-1150.

17. Abell TL, Bernstein RK, Cutts T, et al. Treatment of gastroparesis: a multidisciplinary clinical review. Neurogastroenterol Motil 2006;18:263-283.

18. Boles RG, Chun N, Senadheera D, Wong LJ. Cyclic vomiting syndrome and mitochondrial DNA mutations. Lancet 1997;350: 1299-1300.

19. Lucarelli S, Corrado G, Pelliccia A, et al. Cyclic vomiting syndrome and food allergy/intolerance in seven children: a possible association. Eur J Pediatr 2000;159:360-363.

20. Sato T, Igarashi N, Minami S, et al. Recurrent attacks of vomiting, hypertension and psychotic depression: a syndrome of periodic catecholamine and prostaglandin discharge. Acta Endocrinol (Copenh) 1988;117:189-197.

21. Taché Y. Cyclic vomiting syndrome: the corticotropin-releasing-factor hypothesis. Dig Dis Sci 1999;44(8 Suppl):79S-86S.
22. Taché Y. Corticotropin releasing factor receptor antagonists: potential future therapy in gastroenterology? Gut 2004;53: 919-921.

23. Ogiso K, Koriyama N, Akao A, et al. Type 1 diabetes complicated with uncontrollable adult cyclic vomiting syndrome: a case report. J Diabetes Metab Disord 2015;14:72.

24. Rashed H, Abell TL, Familoni BO, Cardoso S. Autonomic function in cyclic vomiting syndrome and classic migraine. Dig Dis Sci 1999;44(8 Suppl):74S-78S.

25. Hockaday JM. Migraine and its equivalents in childhood. Dev Med Child Neurol 1987;29:265-270.

26. Arborelius L, Owens MJ, Plotsky PM, Nemeroff CB. The role of corticotropin-releasing factor in depression and anxiety disorders. J Endocrinol 1999;160:1-12.

27. Chang HS, Won E, Lee HY, Ham BJ, Lee MS. Association analysis for corticotropin releasing hormone polymorphisms with the risk of major depressive disorder and the response to antidepressants. Behav Brain Res 2015;292:116-124.

28. Mitchelson F. Pharmacological agents affecting emesis: a review (Part II). Drugs 1992;43:443-463. 